\title{
Positive real-world effectiveness of tafamidis for delaying disease progression in transthyretin familial amyloid polyneuropathy
}

\author{
Michelle Stewart, Denis Keohane, Sarah Short, Jose Alvir, Moh-Lim Ong, Rajiv Mundayat \\ From First European Congress on Hereditary ATTR amyloidosis \\ Paris, France. 2-3 November 2015
}

\section{Background}

Tafamidis (Vyndaqel) was approved by the EMA in 2011 and is emerging as the standard of care for transthyretin familial amyloid polyneuropathy (TTR-FAP) in clinical settings. Efficacy was demonstrated in the clinical trials, yet little is known about its real-world effectiveness. A global disease registry, the Transthyretin Amyloidosis Outcomes Survey (THAOS), collects data on both treated and untreated patients from real-world settings. Ethics committee approval was obtained prior to patient enrolment.

\section{Objective}

To demonstrate the real-world effectiveness of tafamidis.

\section{Methods}

THAOS registry data were used to match 258 treated patients to untreated controls in a 1:4 non-randomized retrospective cohort study. Genetic mutation, birth region, and propensity scores derived from clinical status variables were used in matching. Descriptive statistics were calculated. Treatment effects were tested by repeated measures analyses with appropriate covariates (age, gender, disease duration, propensity score, and baseline values).

\section{Results}

The matched sample was predominantly Val30Met (93\%) with roughly equal gender ratio (52\% male) and an average age of 41.4 years. Less disease progression was seen in the tafamidis treated group over 24 months on neurological and quality of life endpoints. The neurologic endpoints with statistically significance favoring tafamidis include the derived NIS-LL and the Neurologic Composite Score

Pfizer Inc., New York, NY, USA including sub-scores. The Norfolk TQoL Score was also statistically significant favoring tafamidis treatment. No significant differences were found for the modified BMI or the Karnofsky Performance Status Index.

\section{Conclusion}

Tafamidis treatment resulted in less neurological progression. The results extend the efficacy observed in the clinical trials to real-world clinical settings.

Published: 2 November 2015

doi:10.1186/1750-1172-10-S1-P4

Cite this article as: Stewart et al:: Positive real-world effectiveness of tafamidis for delaying disease progression in transthyretin familial amyloid polyneuropathy. Orphanet Journal of Rare Diseases 2015 10(Suppl 1):P4.
Submit your next manuscript to BioMed Central and take full advantage of:

- Convenient online submission

- Thorough peer review

- No space constraints or color figure charges

- Immediate publication on acceptance

- Inclusion in PubMed, CAS, Scopus and Google Scholar

- Research which is freely available for redistribution

Submit your manuscript at www.biomedcentral.com/submit
() Biomed Central 